\title{
Reviews on biopolymers, ionic liquids, and related subjects can be found in Issue 9
}

Pharmacologically active salts and ionic liquids based on 2-hydroxyethylamines, aryl chalcogenides, and essential metals

A. N. Mirskova, S. N. Adamovich, R. G. Mirskov, and M. G. Voronkov

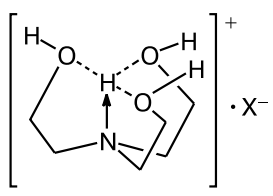

Protatranes

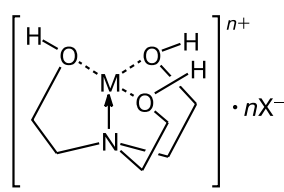

Hydrometallatranes

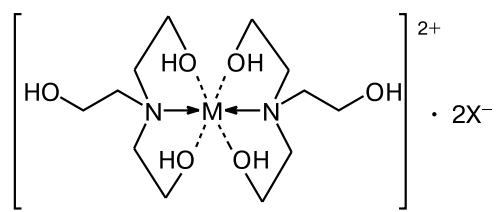

Metallatranes

Quaternary ammonium derivatives of natural terpenoids. Synthesis and properties

V. E. Kataev, I. Yu. Strobykina, and L. Ya. Zakharova
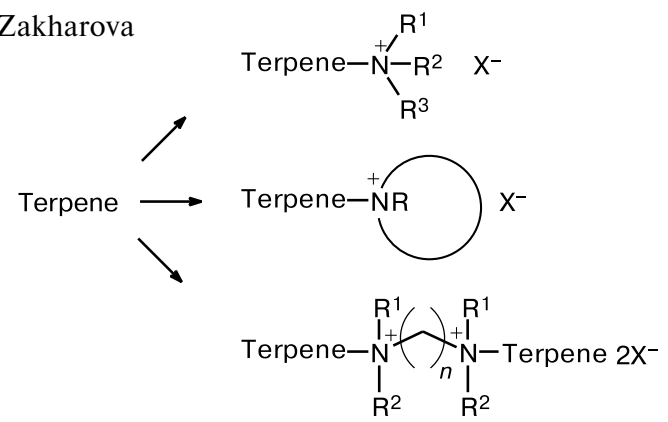

Pectic polysaccharides: structure and properties

O. A. Patova, V. V. Golovchenko, and Yu. S. Ovodov

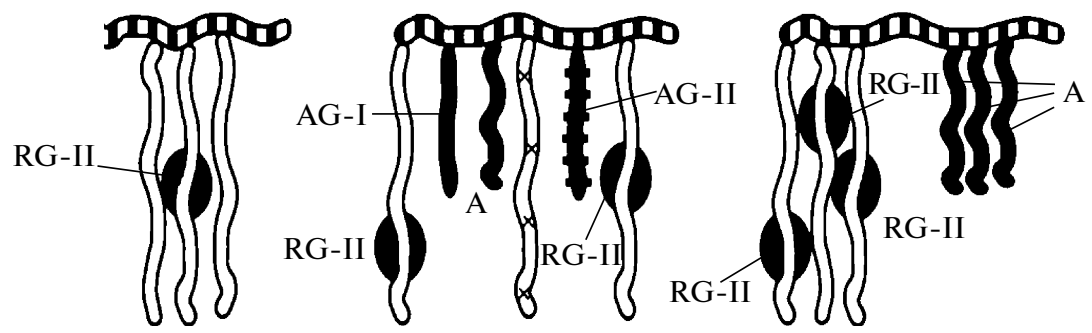

Schematic representation of a family of pectic polysaccharides

Interaction of cellulose and lignocellulose polymers with water and water-organic media

A. N. Prusov, S. M. Prusova, and A. G. Zakharov

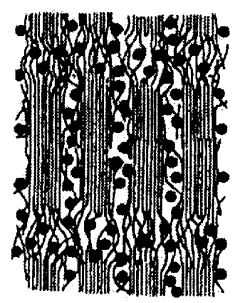

Swollen cellulose matrix with

incorporated solvent molecules 